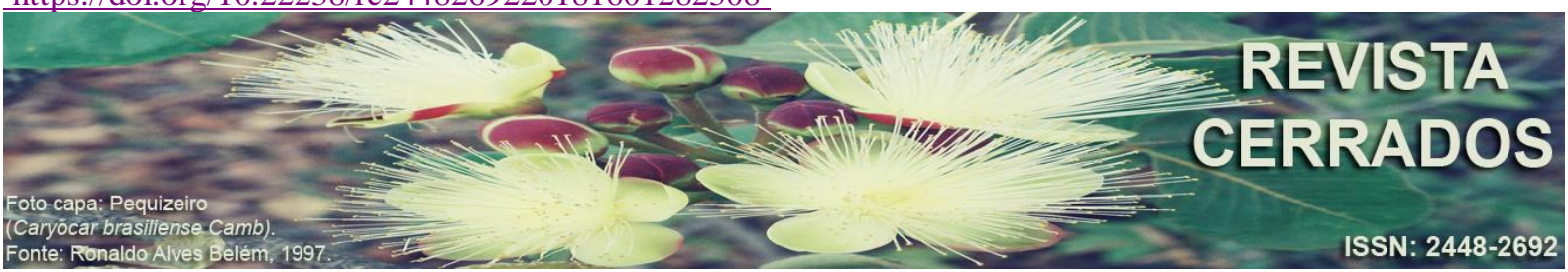

\title{
(TRANS)FORMAÇÃO DO MUNICÍPIO DE CONFINS E SEU PLANEJAMENTO TERRITORIAL
}

\section{(TRANS)TRAINING OF THE MUNICIPALITY OF CONFINS AND ITS TERRITORIAL PLANNING}

\section{(TRANS)FORMACIÓN DEL MUNICIPIO DE CONFINS Y SU PLANIFICACIÓN TERRITORIAL}

\author{
Rogério Augusto Figueiredo Coutinho \\ Universidade Estadual de Montes Claros - UNIMONTES \\ E-mail: <rcoutinho.adv@hotmail.com>. \\ Antônio Dimas Cardoso \\ Universidade Estadual de Montes Claros - UNIMONTES \\ E-mail: <dimascardoso@uol.com.br>. \\ Simone Narciso Lessa \\ Universidade Estadual de Montes Claros - UNIMONTES \\ E-mail: <monelessa@ hotmail.com>.
}

\begin{abstract}
RESUMO
O ordenamento e planejamento territorial dos municípios vêm sofrendo intensas e profundas mudanças, seja pela imposição das forças produtivas e do capital, ou ainda pela necessidade de se adotar novos arranjos territoriais que atendam determinadas necessidades e particularidades locais, trazendo na sua esteira transformações de ordem socioeconômicas e ambientais, levando a vários tipos de investimento em planejamento com abordagens diferenciadas. O último processo de planejamento da Região Metropolitana de Belo Horizonte, qual seja, o Plano Diretor de Desenvolvimento Integrado da Região Metropolitana de Belo Horizonte (PDDI-RMBH, 2009/2011), e o seu respectivo Macrozoneamento (MZ$\mathrm{RMBH}$, 2014), apontaram para a evidenciação da ocorrência de alguns processos socioespaciais desencadeados a partir de ações governamentais estruturantes, como é o caso do município de Confins, que já alterou toda sua legislação específica para estabelecer que o perímetro urbano, tal como definido no Plano Diretor vigente (Lei Complementar $\mathrm{n}^{\mathbf{o}}$ 012/2009), corresponde à totalidade das divisas municipais. Transformou, pois, todas as áreas/zonas rurais em áreas/zonas urbanas ou de expansão urbana. Buscou-se com esse estudo entender em que medida esse processo realizado em Confins foi derivado de disputas entre os vários interesses implicados na formação e no planejamento da Metropolitana de Belo

Licenciada sob Creative Commons (cc) $1 \mathrm{EY}-\mathrm{Ha}-\mathrm{HL}$

Revista Cerrados, Departamento de Geociências e Programa de Pós-Graduação em Geografia (UNIMONTES)
\end{abstract}


Horizonte. A justificativa do trabalho consistiu na importância de, por meio do estudo e análise dos efeitos desse processo de territorialização do município de Confins, jogar luz sobre o papel do Aeroporto (AITN), da pressão imposta pela implantação da Cidade Administrativa e do Vetor Norte, desembocando, em tese, na supressão dos espaços rurais, e, via de consequência, na produção dos correlatos espaços urbanos.

Palavras-chave: Metrópole. Lugar. Território. Aeroporto. Confins. Região metropolitana.

\begin{abstract}
The planning and territorial planning of municipalities are undergoing intense and profound changes, either by the imposition of productive forces and capital, or by the need to adopt new territorial arrangements that meet certain local needs and particularities, bringing in its wake socioeconomic transformations And environmental, leading to various types of planning investment with differentiated approaches. The last planning process of the Metropolitan Region of Belo Horizonte, namely the Integrated Development Master Plan of the Metropolitan Region of Belo Horizonte (PDDI-RMBH, 2009/2011), and its respective Macrozoneamento (MZ-RMBH), pointed to The evidence of the occurrence of some sociospatial processes triggered by structural governmental actions, as is the case of the municipality of Confins, which has already changed all its specific legislation to establish that the urban perimeter, as defined in the current Master Plan (Complementary Law No. 012 / 2009), corresponds to the totality of the municipal currencies. It has thus transformed all rural areas / areas into urban areas or areas of urban expansion. This study sought to understand to what extent this process carried out in Confins was derived from disputes between the various interests involved in the formation and planning of the Metropolitana de Belo Horizonte. The justification of this work was the importance of studying the effects of this process of territorialization in the city of Confins, to shed light on the role of the Airport (AITN), the pressure imposed by the implementation of the Administrative City and the North Vector, Leading to the suppression of rural spaces, and consequently, in the production of related urban spaces.
\end{abstract}

Keywords: Metropolis. Place. Territory. Airport. Confins. Metropolitan region.

\title{
RESUMEN
}

El ordenamiento y planificación territorial de los municipios vienen sufriendo intensos y profundos cambios, sea por la imposición de las fuerzas productivas y del capital, o por la necesidad de adoptar nuevos arreglos territoriales que atiendan determinadas necesidades y particularidades locales, trayendo en su estera transformaciones de orden socioeconómicas y ambientales, llevando a varios tipos de inversión en planificación con enfoques diferenciados. El último proceso de planificación de la Región Metropolitana de Belo Horizonte, es decir, el Plan Director de Desarrollo Integrado de la Región Metropolitana de Belo Horizonte (PDDIRMBH, 2009/2011), y su respectivo Macrozoneamiento (MZ-RMBH, 2014), se ha señalado para la evidencia de la ocurrencia de algunos procesos socioespaciales desencadenados a partir de acciones gubernamentales estructurantes, como es el caso del municipio de Confins, 
COUTINHO, R. A. F.; CARDOSO, A. D.; LESSA, S. N.

(Trans)formação do município de confins e seu planejamento territorial

que ya alteró toda su legislación específica para establecer que el perímetro urbano, tal como se define en el Plan Director vigente (Ley Complementar $n^{\circ}$ 012/2009), corresponde a la totalidad de las divisas municipales. Transformó, pues, todas las áreas / zonas rurales en áreas / zonas urbanas o de expansión urbana. Se buscó con ese estudio entender en qué medida ese proceso realizado en Confins fue derivado de disputas entre los diversos intereses implicados en la formación y en la planificación de la Metropolitana de Belo Horizonte. La justificación del trabajo consistió en la importancia de, a través del estudio y análisis de los efectos de ese proceso de territorialización del municipio de Confins, arrojar luz sobre el papel del Aeropuerto (AITN), de la presión impuesta por la implantación de la Ciudad Administrativa y del Vector Norte, desembocando, en tesis, en la supresión de los espacios rurales, y, por consiguiente, en la producción de los correlatos espacios urbanos.

Palabras clave: Metrópoli. Lugar. Territorio. Aeropuerto. Confins. Región metropolitana.

\section{INTRODUÇÃOO}

O ordenamento e planejamento territorial dos municípios vêm sofrendo intensas e profundas mudanças, seja pela imposição das forças produtivas e do capital, ou ainda pela necessidade de se adotar novos arranjos territoriais que atendam determinadas necessidades e particularidades locais, trazendo na sua esteira transformações de ordem socioeconômicas e ambientais. As áreas metropolitanas se configuram como regiões críticas, concentrando em grandes aglomerados riquezas, mas também problemas sociais e ambientais. Nas últimas décadas, os problemas observados nas regiões metropolitanas levaram a vários tipos de investimento em planejamento com abordagens diferenciadas.

A Região Metropolitana de Belo Horizonte (RMBH), criada no primeiro processo de metropolização gerado pelo Plano Nacional de Desenvolvimento I (PND I), no Governo Militar, tem passado por esses processos históricos de planejamento e apresenta, assim como nas outras regiões metropolitanas brasileiras, um crescimento constante da sua área, população e gestão territorial. O último processo de planejamento da Região Metropolitana de Belo Horizonte, qual seja, o Plano Diretor de Desenvolvimento Integrado da Região Metropolitana de Belo Horizonte (PDDI-RMBH, 2009/2011), apontou para a evidenciação de alguns processos socioespaciais, tais como a formação do Vetor Norte, da Linha Verde e do Aeroporto Internacional Tancredo Neves como novas centralidades. Na RMBH, alguns municípios - como é o caso de Confins/MG - alteraram legalmente os seus zoneamentos 
territoriais, para transformação de suas zonas rurais em áreas exclusivamente urbanas ou de expansão urbana, estabelecendo novos modos de apropriação do espaço.

Visando entender parte desses processos, este trabalho teve como recorte espacial o município de Confins, município que hospeda a maior parte territorial do Aeroporto Internacional Tancredo Neves (AITN), além de ser um dos municípios dentro da RMBH que já alterou toda sua legislação específica para estabelecer que o perímetro urbano, tal como definido no Plano Diretor vigente ${ }^{1}$, corresponde à totalidade das divisas municipais.

O recorte temporal compreendeu o ano de 2009 - período das alterações legislativas que extinguiu o zoneamento rural de Confins, coincidente, ainda, com o início da elaboração do PDDI-RMBH, delimitado ao ano de 2016 -, data das últimas informações e produtos disponibilizados pela Agência de Desenvolvimento da Metropolitana de Belo Horizonte (ARMBH), seja quanto ao PDDI, seja quanto ao MZ-RMBH.

Assim, este trabalho pôs em questão os processos de territorialização que formaram o município de Confins, e, a partir de 2009, os processos que levaram a um rearranjo do seu território. Em que medida eles foram derivados de disputas entre os vários interesses implicados na formação e no planejamento da Metropolitana de Belo Horizonte?

A metodologia utilizada para o desenvolvimento do trabalho foi a análise documental e a investigação dos processos históricos, socioeconômicos e territoriais, a partir da análise de fontes secundárias, como dados do Instituto Brasileiro de Geografia e Estatística (IBGE), bibliografia sobre o tema; documentos governamentais, leis, planos e iconografia; fontes primárias, dados coletados em campo, como depoimentos e registros fotográficos.

\section{A MEtropolitana DE BELO HORIZONTE E SEUS PROCESSOS DE PLANEJAMENTO TERRITORIAL}

A Região Metropolitana de Belo Horizonte (RMBH) transformou-se intensa e rapidamente desde sua criação, tanto em tamanho e extensão, quanto em sua natureza e

\footnotetext{
${ }^{1}$ Lei Complementar $n^{\circ} 012 / 2009$.
}

Revista Cerrados, Montes Claros/MG, v.16, n. 1, p. 282-308, jan./jun.-2018. 
COUTINHO, R. A. F.; CARDOSO, A. D.; LESSA, S. N.

(Trans)formação do município de confins e seu planejamento territorial

características. No ano de sua criação ${ }^{2}$, em 1973, a RMBH contava com 14 municípios e 1,7 milhões de habitantes. Em 2016 se caracterizava como a terceira maior aglomeração urbana do Brasil com mais de 5 milhões de habitantes nos seus 34 municípios.

FIGURA 01 - Região Metropolitana de Belo Horizonte e Colar Metropolitano

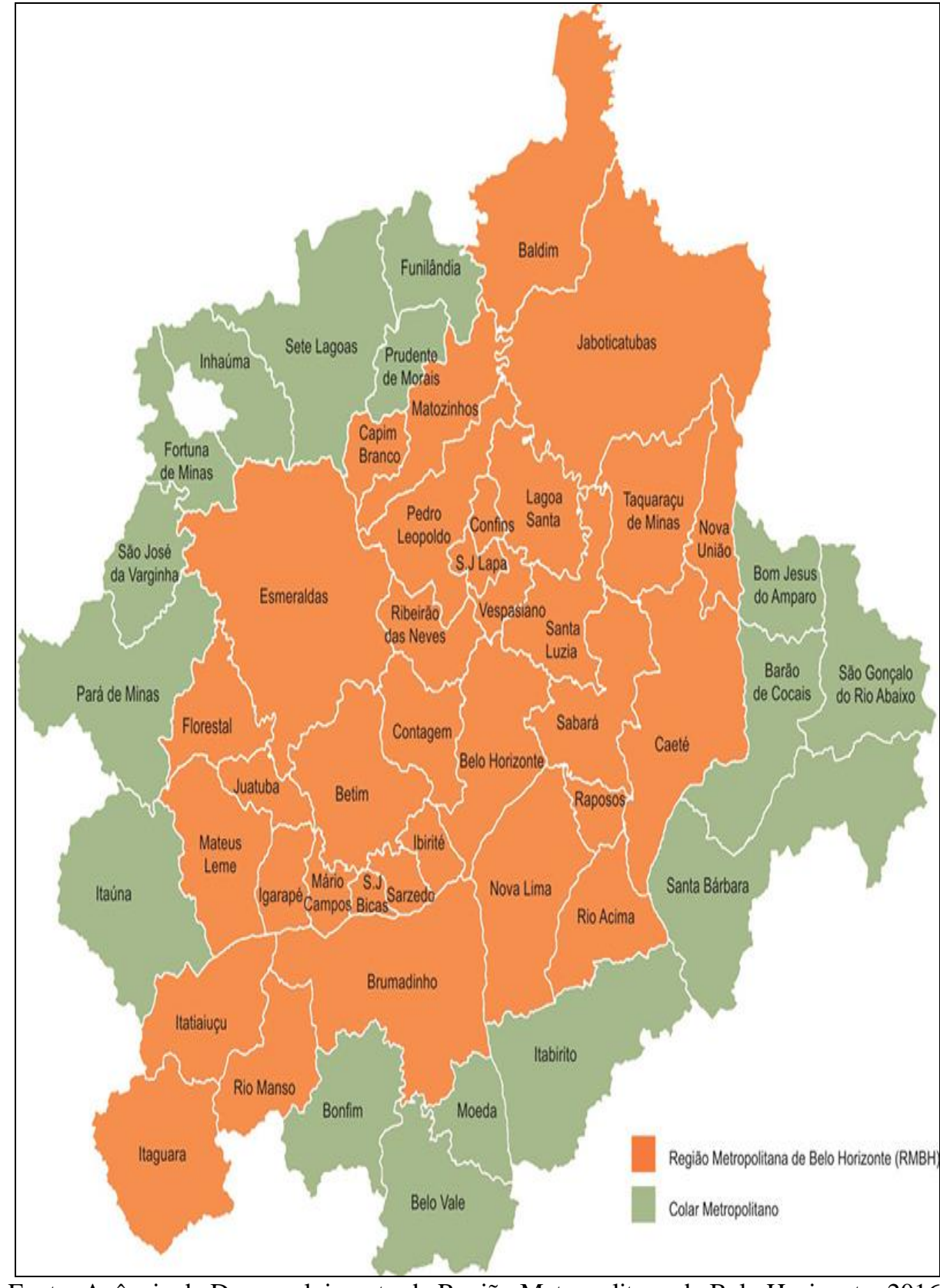

Fonte: Agência de Desenvolvimento da Região Metropolitana de Belo Horizonte, 2016.

\footnotetext{
${ }^{2}$ Lei Complementar Federal n. ${ }^{\circ}$ 14/73, e, atualmente, é regulamentada por leis complementares do Estado de Minas Gerais (LEC n. ${ }^{\circ} 88 / 2006$ e LEC n. ${ }^{\circ} 89 / 2006$ ).
}

Revista Cerrados, Montes Claros/MG, v.16, n. 1, p. 282-308, jan./jun.-2018. 
COUTINHO, R. A. F.; CARDOSO, A. D.; LESSA, S. N.

(Trans)formação do município de confins e seu planejamento territorial

A RMBH foi favorecida e impactada pelo esforço de industrialização da economia mineira a partir do final dos anos 1960, apesar de ainda não constituída legalmente. Houve um adensamento e diversificação da matriz industrial do complexo minerometalúrgico, resultando na criação de um estruturante complexo metal-mecânico na Região. Consequentemente, parte expressiva dos municípios do entorno metropolitano se industrializou e o município de Belo Horizonte progrediu em direção a serviços produtivos modernos. O Vetor Norte expandiu de forma acelerada em direção a espaços mais distantes, em um processo induzido por uma série de investimentos estruturantes do Governo do Estado, ao mesmo tempo em que ampliou a sua área polarizada para o Colar Metropolitano e mesmo para polos microrregionais e regionais do seu entorno ampliado.

O Plano Diretor de Desenvolvimento Integrado da Região Metropolitana de Belo Horizonte (PDDI-RMBH) foi elaborado entre 2009 e 2011, buscando ser uma referência de planejamento para os 34 municípios da $\mathrm{RMBH}$, assim como dos 16 municípios que integram o colar metropolitano, nas próximas décadas. Dessa experiência, a nosso ver, o processo de extinção legislativo da zona rural do município de Confins é o mais impactante socialmente. A nossa hipótese é de que o município de Confins não reagiu de forma satisfatória às investidas e intervenções do Estado (requalificação do AITN, Cidade Administrativa, Linha Verde - Vetor Norte).

\section{A ANÁLISE DA TRAJETÓRIA DE TERRITORIALIZAÇÃO DO MUNICÍPIO DE CONFINS E OS ELEMENTOS ESTATAIS DE T-D-R}

A criação e reestruturação do Aeroporto Internacional Tancredo Neves (AITN), aparentemente, não atribui uma função significativa à cidade e ao município de Confins, quem dirá os demais empreendimentos de indução da vetorização norte da Metropolitana que também impactaram e impactam socioespacialmente tal município (Linha Verde/Avenida Cristiano Machado e "Cidade Administrativa" - sede dos órgãos públicos do Governo de Minas Gerais), o que implica a necessidade de uma reconstrução da lógica que levou Confins a se afastar de sua vocação originária de atividades rurais, para rever o seu arcabouço legal e considerar a totalidade das divisas municipais como perímetro urbano ou de expansão urbana. 
COUTINHO, R. A. F.; CARDOSO, A. D.; LESSA, S. N.

(Trans)formação do município de confins e seu planejamento territorial

Durante visitas de campo verificou-se que a emancipação ${ }^{3}$ de Confins não foi norteada apenas por uma vontade política do Governo de Minas Gerais, mas muito antes se deu por força de mobilização da sociedade, de modo a se reivindicar melhorias e investimentos públicos para o então distrito de Lagoa Santa. Todavia, é importante reconhecer que a imposição das forças produtivas e do capital, quase sempre importa na concepção e implantação de infraestrutura para otimizar as relações de mercado, o que no caso de Confins foi inteiramente assumido pelo Estado, ao se criar e instalar o AITN, em 1984, ou seja, muito antes de qualquer movimento emancipatório. É importante registrar, portanto, que desde o início da década 1980, já se verificava a pressão da Metropolitana em torno do território de Confins.

O Aeroporto, desde o seu nascedouro, surge como elemento transformador do lugar, gerando implicações socioterritoriais, certamente acentuadas pela emancipação de Confins, que trouxe expectativas de mudanças positivas relacionadas ao desenvolvimento territorial e econômico. Em campo, ainda se pôde constatar o fato de que a instalação do AITN somente se mostrou possível mediante processos de desapropriação de famílias residentes naquele espaço, famílias essas que mantinham atividades produtivas em suas propriedades, próprias de agricultura familiar e de subsistência, e que, portanto, tiveram ali um primeiro impacto quanto as suas práticas socioeconômicas e culturais e de desconexão identitária.

Ao se abordar a produção do espaço a partir da territorialização do AITN (e lado outro, processo de desterritorialização da população nativa), não se pode fugir da constatação de que o Estado atacou a qualidade e forma de viver daquela população então residente no local de instalação do empreendimento, e também do entorno da área diretamente afetada. Aliás, como é de praxe se observar em qualquer relação que implique na requalificação do espaço, seja física ou econômica.

A partir dessa constatação se pode firmar a hipótese de que o município de Confins não reagiu de forma satisfatória às investidas e intervenções do Estado (Vetor Norte requalificação do AITN, Cidade Administrativa, Linha Verde). Daí se percebeu então um

\footnotetext{
${ }^{3}$ Elevado á categoria de município coma denominação de Confins, pela lei estadual no 12030, de 21-12-1995, desmembrado de Lagoa Santa. Sede no antigo distrito de Confins. Constituído do distrito sede. Instalado em $01-$ 01-1997.
}

Revista Cerrados, Montes Claros/MG, v.16, n. 1, p. 282-308, jan./jun.-2018. 
segundo movimento que também veio alterar as relações socioespaciais da população do município de Confins, agora mais abrangente que o primeiro, pois não afetou apenas a população da área do empreendimento diretamente envolvida do AITN, mas de toda a população das áreas/zonas rurais suprimidas do município de Confins.

Antes da entrada em vigor da Lei Complementar $\mathrm{n}^{\circ}$ 12/2009, que revisou e alterou o primeiro Plano Diretor de Confins ${ }^{4}$, para suprimir do seu ordenamento territorial as áreas/zonas rurais, se tinha a expressa previsão legal do zoneamento rural no município, melhor qualificando, se regulava a ZUS - Zona de Usos Sustentáveis -, compreendendo áreas para o desenvolvimento de atividades rurais compatíveis com o ambiente cárstico, bem como empreendimentos isolados, ambientalmente sustentáveis.

O $1^{\circ}$ Plano Diretor previa expressamente o resguardo da ZUS (Zona de Usos Sustentáveis), com a expressa garantia do território para o desenvolvimento das atividades rurais $^{5}$, ao passo que na legislação vigente - revisão do Plano Diretor -, somente se tolera as atividades rurais naqueles territórios em que inviáveis o parcelamento do solo para fins urbanos $^{6}$, conceito esse que é considerado abstrato para regulação e parcelamento do solo.

Além do disposto na LC 002/1999, que resguardava as ZUS, a apontada legislação ainda garantia o compromisso de incentivo às atividades rurais, através da elaboração de um plano de incentivo (art. $6^{\circ}$ ). Todavia, com a revisão do Plano Diretor, tevese por bem simplesmente suprimir tal zoneamento para conformar todo o território municipal como zona urbana e zona de expansão urbana, desconsiderando toda uma construção socioespacial e cultural secular.

Visível, pois, uma desconexão entre a leitura do arcabouço legal do município e aquela retratada no território, observada, sobremodo, pelo levantamento e tratamento dos dados secundários trabalhados em tópico próprio, e também daquela observada em trabalhos de campo. Desconexão ainda e, sobretudo, observada entre a atividade normalizadora do município de Confins e os novos paradigmas trazidos no PDDI-RMBH e, principalmente, no MZ-RMBH.

\footnotetext{
${ }^{4}$ Lei Complementar 002/1999.

${ }^{5}$ Inciso VII, do art. $9^{\circ}$, da Lei Complementar n ${ }^{\circ}$ 002/1999.

${ }^{6}$ Iinciso IX, do art. 12, da Lei Complementar no 012/2009.

Revista Cerrados, Montes Claros/MG, v.16, n. 1, p. 282-308, jan./jun.-2018.
} 
COUTINHO, R. A. F.; CARDOSO, A. D.; LESSA, S. N.

(Trans)formação do município de confins e seu planejamento territorial

FIGURA 02 - Zoneamento Municipal de Confins

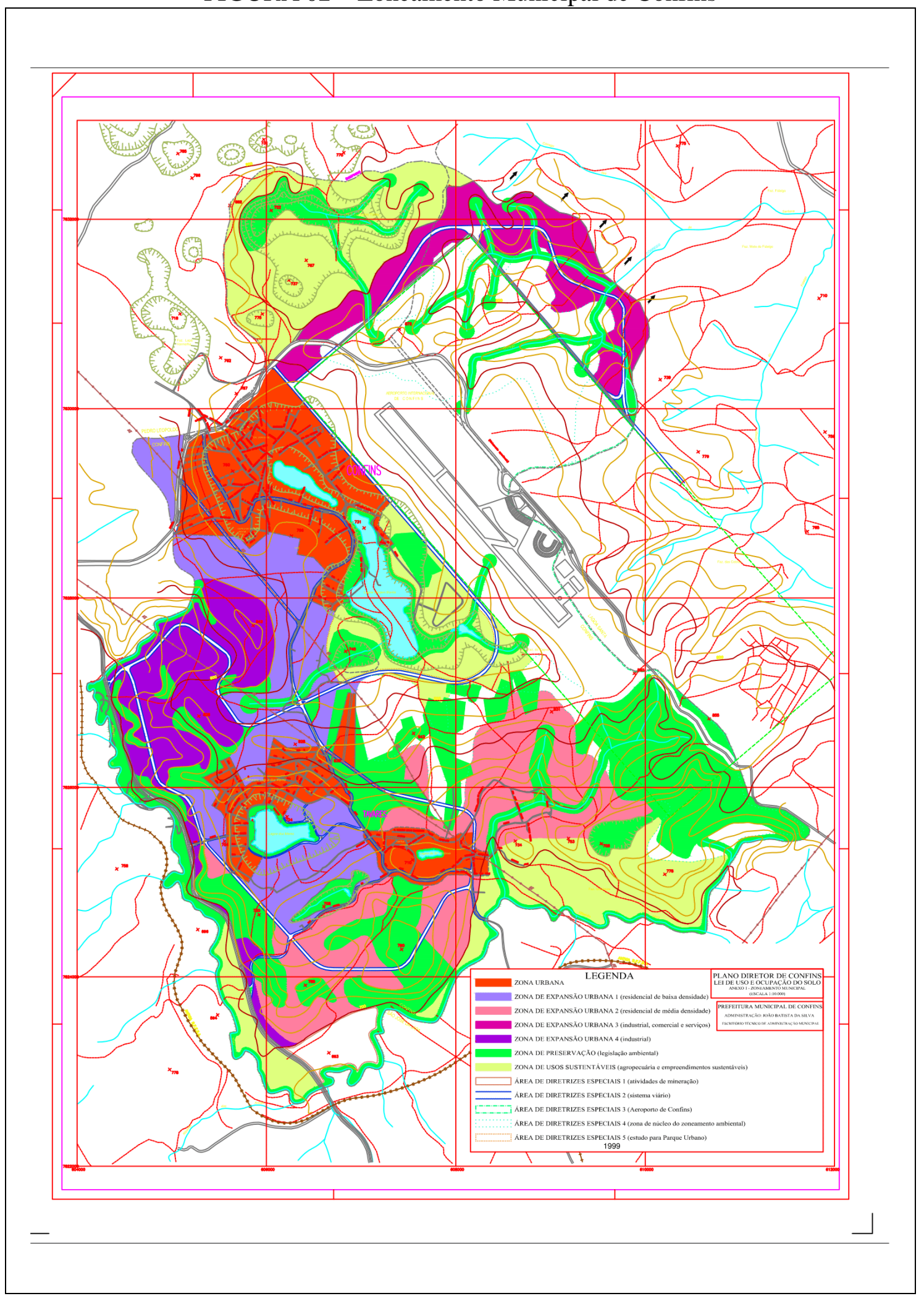

Fonte: Anexo I, Plano Diretor Municipal de Confins, 1999.

Revista Cerrados, Montes Claros/MG, v.16, n. 1, p. 282-308, jan./jun.-2018. 
COUTINHO, R. A. F.; CARDOSO, A. D.; LESSA, S. N.

(Trans)formação do município de confins e seu planejamento territorial

\section{O RURAL (IN)EXISTENTE OU RESISTENTE}

Nesse contexto de atividades agropecuárias desenvolvidas, as cidades tornaram-se pontos de conexão entre o rural e o urbano e, deste, com o mundo globalizado. Para Lefebvre (1999), existem diferenças que separam os conceitos de urbano e cidade. A cidade é um fenômeno emergente desde a antiguidade, resultante também da separação campo-cidade, a partir da divisão social do trabalho. E pode ser definida como a base material e arquitetônica, de forma concreta, prático-sensível, no qual o processo histórico evolui de forma dialética e multifuncional. O urbano pode ser definido como a "realidade social composta de relações a serem concebidas, construídas ou reconstruídas pelo pensamento.” (LEFEBVRE, 1991, p. 49). Para isso, Lefebvre (2008) afirma que as transformações nas cidades são produzidas pela apropriação dos habitantes que as ocupam e, por isso, os espaços urbanos são sempre um produto inacabado.

Esse espaço depende de interesses divergentes e de grupos diversos que, no entanto, encontram uma unidade no Estado (...). Quanto à divisão do trabalho entre os que intervêm no espaço, a saber, o arquiteto, o promotor imobiliário, o urbanista, o empreendedor etc. (LEFEBVRE, 2008, p. 53).

O uso do solo da RMBH revela a dinâmica de processos econômicos, políticos e sociais sobre um território de características bem distintas. Analisando-se as áreas não urbanizadas observa-se a influência das características físicas e dos atributos do sítio natural. Ao sul, desde sudoeste a sudeste (área do quadrilátero ferrífero), destacam-se as minerações. Ao norte, ao contrário, as terras mais férteis e de relevo menos acidentado propiciam o uso tipicamente rural com atividades agropecuárias mais estruturadas, junto à exploração de calcário, na grande área cárstica, e de areia ao longo dos cursos d'água.

E essa dinâmica de processos econômicos com relação ao uso do solo sempre desvelou a aptidão eminentemente rurícola de Confins. Todavia, diante de todos os processos expansionistas da Metropolitana, em especial o do Vetor Norte, o que se denota é a reconfiguração socioespacial do município de Confins, deflagrada por um ímpeto legislativo em amparar os processos de desmembramento e parcelamento do solo.

Revista Cerrados, Montes Claros/MG, v.16, n. 1, p. 282-308, jan./jun.-2018. 
COUTINHO, R. A. F.; CARDOSO, A. D.; LESSA, S. N.

(Trans)formação do município de confins e seu planejamento territorial

\section{DO RURAL AO URBANO E A BUSCA PELA MAIS-VALIA FUNDIÁRIA}

A aptidão rural do território de Confins foi subvertida desde a emancipação do município, e, posteriormente, suplantada por uma mera alteração no seu Plano Diretor, desconsiderando identidades, tradições e o modo de viver da sua população. No espaço urbanizado, os dados secundários e análise da fonte documental - coletados junto a Prefeitura Municipal de Confins - indicaram a ocorrência de vários tipos de parcelamento, ocupação e uso do solo, associados a processos específicos, que vão desde “Áreas de ocupações espontâneas tradicionais" aos "Condomínios fechados", voltados para camadas de alta renda, aos "Parcelamentos desocupados, com carência de infraestrutura".

As principais características que marcam e se sobressaem no Vetor Norte, considerando a relação com o processo de ocupação da metrópole, são: no eixo Norte, ocupação ainda bastante horizontal em parcelamentos com carência de infraestrutura e, nos municípios mais próximos a Belo Horizonte, tendência a alguma verticalização nas áreas bem servidas de infraestrutura e mais próximas da Cidade Administrativa, cuja implantação tem resultado em grande valorização do entorno. Vê-se também a intensificação dos condomínios residenciais fechados, voltados para população de alta renda, especialmente nos municípios com esse histórico de ocupação, como é o caso de Lagoa Santa e Confins.

Nos demais municípios da RMBH ainda predominam tipos de ocupação mais característicos de cidades sem grande "comprometimento" com a metropolização, embora, nas duas últimas décadas, constata-se a implantação, principalmente na direção da Serra do Cipó, de sítios de lazer e condomínios fechados de alta renda. Até 2016, verifica-se ainda o adensamento dos assentamentos precários voltados para a população de baixa renda, especialmente nas áreas de melhor acesso viário, como aquelas ao longo da BR-424 para Pedro Leopoldo.

A implantação de projetos estruturantes, assim denominados pelo potencial que possuem de influenciar o uso e a ocupação no entorno, via de regra, produz valorização dos terrenos e propriedades, que resultam em novos arranjos, quase sempre com a expulsão dos antigos usuários. As possibilidades de interferências urbanísticas nestes processos, no sentido de favorecer a coletividade e, em especial, populações de menor renda e competitividade no 
COUTINHO, R. A. F.; CARDOSO, A. D.; LESSA, S. N.

(Trans)formação do município de confins e seu planejamento territorial

mercado imobiliário, tornaram-se mais factíveis a partir da utilização de instrumentos do Estatuto da Cidade. No entanto, tal leitura permite verificar a transformação territorial observada em Confins, onde se visualiza a imposição de um expansionismo em detrimento das atividades tradicionais rurais. $\mathrm{O}$ ato legislativo legitima a supressão da zona rural no município.

Partindo da definição de que "a cidade é uma obra” (LEFEBVRE, 2001, p. 12), pode-se afirmar que a cidade é um local de criação de estabelecimentos de centralidades, de combinações e transformações de relações sociais. De acordo com o sociólogo e filósofo francês, sob o capitalismo, a cidade, enquanto "projeção da sociedade sobre um local" (LEFEBVRE, 1991, p. 12), torna-se cada vez mais um produto, um valor de troca, a ser consumido.

Na concepção de Ribeiro (1997), a terra urbana seria um bem não produzido pelo trabalho, sendo na realidade preexistente a qualquer trabalho e dessa forma seu preço não estaria regulado pela lei do valor. Como se formaria então o preço da terra? As pessoas teriam de pagar pelo uso de um bem não produzido, de uma dádiva da natureza? Para "Ribeiro", o preço da terra seria formado considerando o monopólio da propriedade privada, a partir da disputa intercapitalista pelo acesso a terra. Não haveria um mercado de terras urbanas, simplesmente pelo fato de ninguém ser capaz de "produzi-la", e, dessa forma, o preço da terra seria totalmente formado pela demanda. O capital imobiliário para Singer (1980) seria um falso capital, pois mesmo sendo um valor que se valoriza, essa valorização é totalmente especulativa já que se baseia numa mercadoria não produzida pelo trabalho humano.

No caso da terra urbana, deve-se considerar dois valores: o valor dos produtos em si, como o valor dos imóveis urbanos, infraestruturas, prédios públicos, e o valor da localização desses imóveis (produtos) dentro da aglomeração. Por fim, a distinção entre os valores da terra urbana é de grande importância teórica, principalmente quando evidenciada a "localização" enquanto técnica de valorização fundiária.

Tal concepção vê a terra urbana, inserida em um espaço urbano fruto do trabalho humano. Assim uma área é mais central porque nela há um maior acúmulo de trabalho social, enquanto uma área é periférica porque nela o acúmulo de trabalho social é menor, sendo, 
COUTINHO, R. A. F.; CARDOSO, A. D.; LESSA, S. N.

(Trans)formação do município de confins e seu planejamento territorial

portanto, as áreas centrais os focos de convergência privilegiados dos agentes econômicos que comandam e articulam os processos de produção da cidade.

Como visto, a dinâmica de inserção de Confins na Metropolitana tem deflagrado nos últimos anos um processo de proliferação de chacreamentos e condomínios fechados, num aparente processo de territorialização para geração de mais-valia fundiária. A ação normalizadora de Confins em extinguir sua zona rural $^{7}$, foi efetivamente levada a efeito no mesmo período de deflagração de todas as obras estruturantes no Vetor Norte, em 2005 (requalificação do AITN), passando pela implantação da Linha Verde (2007) e pela instalação da Cidade Administrativa (2010), até a consolidação do PDDI-RMBH (2009/2011) e o MZRMBH (2014), como forma mesmo de permitir com maior facilidade o parcelamento do solo nas "novas" zonas urbanas ou de expansão urbana, de modo a atrair novos empreendimentos imobiliários e industriais.

\section{DINÂMICA DEMOGRÁFICA E ECONÔMICA DE CONFINS - A PERSISTÊNCIA DO RURAL EM CONFINS}

Para uma leitura mais abrangente da dinâmica demográfica e econômica de Confins, torna-se imperativo uma análise conjunta com a trajetória do município de Lagoa Santa, haja vista a relação de comunicabilidade de um município com o outro, ressaltando: $(i)$ a emancipação do então distrito de Confins do município de Lagoa Santa somente em 1995, e (ii) a existência de equipamentos públicos e privados (destaca-se o AITN), empreendimentos imobiliários e áreas de conservação ambiental em ambos os territórios.

As tabelas 01 a 03 abaixo colacionadas demonstram a evolução demográfica desde o censo de 1991, sendo que 2010 (IBGE), em Lagoa Santa existiam 52.526 habitantes, enquanto em Confins, 5.943 habitantes, sendo todos da zona urbana, em razão da alteração do Plano Diretor datado de 2009 que extinguiu a zona rural daquele município.

\footnotetext{
${ }^{7}$ Lei Complementar 12/2009.
}

Revista Cerrados, Montes Claros/MG, v.16, n. 1, p. 282-308, jan./jun.-2018. 
COUTINHO, R. A. F.; CARDOSO, A. D.; LESSA, S. N.

(Trans)formação do município de confins e seu planejamento territorial

TABELA 01 - População Censo 1991 - IBGE

\begin{tabular}{|c|c|c|c|}
\hline $\begin{array}{c}\text { Unidade Administrativa - } \\
\text { Município }\end{array}$ & $\begin{array}{c}\text { Total população } \\
\text { urbana }\end{array}$ & $\begin{array}{c}\text { Total população } \\
\text { rural }\end{array}$ & $\begin{array}{c}\text { Total da população } \\
\text { em 1991 }\end{array}$ \\
\hline Belo Horizonte & 2.103 .257 & 6.904 & 2.020 .161 \\
\hline Confins & 3.087 & 96 & 3.183 \\
\hline Lagoa Santa & 27.979 & 1.845 & 29.824 \\
\hline
\end{tabular}

Fonte: Censo Demográfico 1991 do IBGE.

TABELA 02 - População Censo 2000 - IBGE

\begin{tabular}{l|c|c|c}
\hline $\begin{array}{c}\text { Unidade Administrativa - } \\
\text { Município }\end{array}$ & $\begin{array}{c}\text { Total população } \\
\text { urbana }\end{array}$ & $\begin{array}{c}\text { Total população } \\
\text { rural }\end{array}$ & $\begin{array}{c}\text { Total da população em } \\
\mathbf{2 0 0 0}\end{array}$ \\
\hline Belo Horizonte & 2.238 .526 & - & 2.238 .526 \\
\hline Confins & 3.126 & 1.754 & 4.880 \\
\hline Lagoa Santa & 35.396 & 2.476 & 37.872 \\
\hline
\end{tabular}

Fonte: Censo Demográfico 2000 do IBGE.

TABELA 03 - População Censo 2010 - IBGE

\begin{tabular}{l|c|c|c}
\hline $\begin{array}{c}\text { Unidade Administrativa - } \\
\text { Município }\end{array}$ & $\begin{array}{c}\text { Total } \\
\text { população } \\
\text { urbana }\end{array}$ & Total população rural & $\begin{array}{c}\text { Total da população em } \\
\mathbf{2 0 1 0}\end{array}$ \\
\hline Belo Horizonte & 2.375 .444 & 0 & 2.375 .444 \\
\hline Confins & 5.943 & $\mathbf{0}$ & 5.943 \\
\hline Lagoa Santa & 48.953 & 3.573 & 52.526 \\
\hline
\end{tabular}

Fonte: Censo Demográfico 2010 do IBGE.

Os municípios integrantes do eixo da Linha Verde também apresentaram expressivas taxas de crescimento demográfico nos períodos 1991-2000 e 2000-2010, excetuando-se Belo Horizonte e Pedro Leopoldo, indicativo da pequena inserção dos mesmos no processo de ocupação da metrópole. Conforme se verifica da tabela abaixo, na última medição (2000/2010), houve um acréscimo populacional em Confins da ordem de 21,78\%, o que demonstra um intenso processo de urbanização, alavancado, em tese, pelas diretrizes expansionistas e obras estruturantes dos Governos Estadual e Federal no Eixo Norte da Metropolitana. 
COUTINHO, R. A. F.; CARDOSO, A. D.; LESSA, S. N.

(Trans)formação do município de confins e seu planejamento territorial

TABELA 04 - Belo Horizonte e municípios integrantes do eixo da Linha

\begin{tabular}{|c|c|c|c|c|c|c|}
\hline \multirow[t]{2}{*}{ Localidade } & \multicolumn{4}{|c|}{ População } & \multicolumn{2}{|c|}{$\begin{array}{l}\text { Taxa média de } \\
\text { crescimento decenal } \\
(\%)\end{array}$} \\
\hline & & 1991 & 2000 & 2010 & $\begin{array}{c}1991- \\
2000\end{array}$ & $\begin{array}{l}2000- \\
2010\end{array}$ \\
\hline \multicolumn{2}{|c|}{ Belo Horizonte } & 2.020 .161 & 2.238 .526 & 2.375 .444 & 10,80 & 6,11 \\
\hline \multirow{5}{*}{$\begin{array}{l}\text { Eixo } \\
\text { da } \\
\text { Linha } \\
\text { Verde }\end{array}$} & Vespasiano & 54.868 & 76.422 & 104.612 & 39,28 & 36,88 \\
\hline & São José da Lapa & 6.856 & 15.000 & 19.801 & 118,78 & 32,00 \\
\hline & Pedro Leopoldo & 41.594 & 53.957 & 58.696 & 29,72 & 8,78 \\
\hline & Lagoa Santa & 29.824 & 37.872 & 52.526 & 26,98 & 38,69 \\
\hline & Confins & 3.183 & 4.880 & 5.943 & 53,31 & 21,78 \\
\hline
\end{tabular}

Fonte: Censos Demográficos 1991, 2000 e 2010, do IBGE.

Em Confins, após a remodelagem do aeroporto AITN (2005), e mais fortemente a partir de 2009, houve um crescimento positivo no Produto Interno Bruto - PIB, e, por consequência, do PIB per capita, sendo de destacar que nem toda a renda gerada no município de Confins é apropriada pela população residente. A geração de renda e o consumo não são necessariamente realizados em um mesmo município, de acordo aponta o IBGE.

Conforme se observa das tabelas seguintes, Confins é o município que tem as características de menor tamanho, mas que tem o maior PIB per capita entre os municípios apresentados. O motivo dessa disparidade pode residir na confluência dos seguintes fatores: presença em seu território do Aeroporto Internacional Tancredo Neves - melhor especificando, de $67 \%$ de tal equipamento - os demais $33 \%$ estão no município de Lagoa Santa; reduzida extensão territorial (pouco mais que $42 \mathrm{~km}^{2}$ ) e a baixa densidade populacional.

TABELA 05 - Características demográficas, geográficas e econômicas de Belo Horizonte, Confins e Lagoa Santa

\begin{tabular}{c|c|c|c}
\hline Características/Cidades & Belo Horizonte & Confins & Lagoa Santa \\
\hline População & 2.375 .444 & 5.936 & 52.526 \\
\hline Área (Km) & 331,401 & 42,355 & 229,267 \\
\hline Densidade Demográfica & 716,00 & 140,15 & 229,08 \\
\hline
\end{tabular}

Fonte: IBGE, 2010. 
COUTINHO, R. A. F.; CARDOSO, A. D.; LESSA, S. N.

(Trans)formação do município de confins e seu planejamento territorial

TABELA 06 - Belo Horizonte e municípios integrantes do eixo da Linha Verde/Vetor Norte - Produto Interno Bruto (PIB) per capita, 2010

\begin{tabular}{l|l|c}
\hline \multicolumn{2}{l}{ Localidade } & \multicolumn{2}{l}{ PIB Per Capita 2010 (R\$) } \\
\hline \multicolumn{2}{l|}{ Belo Horizonte } & $21.750,94$ \\
\hline \multirow{2}{*}{$\begin{array}{l}\text { Eixo } \\
\text { Linha }\end{array}$} & Vespasiano & $12.572,60$ \\
\cline { 2 - 3 } \multirow{2}{*}{ Verde } & São José da Lapa & $16.063,74$ \\
\cline { 2 - 3 } & Pedro Leopoldo & $17.879,09$ \\
\cline { 2 - 3 } & Lagoa Santa & $16.116,68$ \\
\cline { 2 - 3 } & Confins & $256.466,00$ \\
\hline
\end{tabular}

Fonte: Instituto Brasileiro de Geografia e Estatística (IBGE) e Centro de Estatística e Informações (CEI) da Fundação João Pinheiro (FJP).

Mesmo diante de todos esses recursos (PIB e PIB per capta), Confins se afigura como um município de reduzidas dimensões, que em termos de atividades comerciais e industriais, não possui uma função tão significativa para a metrópole. A economia é predominantemente de serviços, pela existência do Aeroporto Internacional Tancredo Neves, o que lhe garante o segundo maior PIB per capita do Estado de Minas Gerais ( $\$ 256$ mil/pessoa) e o quarto do país ${ }^{8}$. O PIB per capita de Confins é 11 (onze) vezes maior que o índice de Belo Horizonte. Esse crescimento na arrecadação de impostos no município é um indicador econômico que sinaliza os investimentos atribuídos ao AITN.

\footnotetext{
${ }^{8}$ De acordo com publicação da Fundação João Pinheiro que divulgou o PIB dos municípios de Minas Gerais, aos 17 de dezembro 2013.

Os dados são parte do boletim divulgado pelo Centro de Estatística e Informações (CEI) da Fundação João Pinheiro (FJP) nesta terça-feira, 17 de dezembro. Disponível no site da instituição (www.fjp.mg.gov.br). O estudo apresenta os resultados do PIB, do PIB per capita e os valores adicionados da agropecuária, indústria, serviços e da administração pública para as 853 cidades mineiras, além dos valores revisados de 2010 .

De acordo com a publicação, o crescimento recente do setor da indústria extrativa mineral impulsionou o desenvolvimento da cidade de São Gonçalo do Rio Abaixo ( $\mathrm{R}$ \$283.298) na região Central, que teve o maior PIB per capita de Minas Gerais. Em segundo lugar, Confins (R\$256.466), também no centro do estado, se destacou pelas atividades do Aeroporto Internacional Tancredo Neves, que passou a operar os principais voos transferidos do Aeroporto da Pampulha desde 2005.

A classificação nacional do PIB per capita das cidades com melhores desempenhos no Estado foi: São Gonçalo do Rio Abaixo $\left(3^{\circ}\right)$, Confins $\left(4^{\circ}\right)$, Araporã $\left(10^{\circ}\right)$, Itatiaiuçu $\left(12^{\circ}\right)$, Mariana $\left(25^{\circ}\right)$, Extrema $\left(37^{\circ}\right)$, Nova Lima $\left(46^{\circ}\right)$, Fortaleza de Minas $\left(48^{\circ}\right)$, Água Comprida $\left(50^{\circ}\right)$ e Catas Altas $\left(51^{\circ}\right)$.

Fonte: Fundação João Pinheiro (FJP), Centro de Estatística e Informações (CEI) - Instituto Brasileiro de Geografia e Estatística (IBGE), Coordenação de Contas Nacionais (CONAC). Elaboração: Fundação João Pinheiro (FJP), Centro de Estatística e Informações (CEI). (www.fjp.mg.gov.br) - < http://www.fjp.mg.gov.br/index.php/noticias-em-destaque/2678-fundacao-joao-pinheiro-divulga-pib-dosmunicipios-de-minas-gerais>. Acesso em: 30 maio 2016, 15:20:00.
} 
COUTINHO, R. A. F.; CARDOSO, A. D.; LESSA, S. N.

(Trans)formação do município de confins e seu planejamento territorial

TABELA 07 - PIB dos municípios brasileiros 1999-2012

\begin{tabular}{|c|c|c|c|c|c|c|c|c|c|}
\hline $\begin{array}{l}\text { Ano de } \\
\text { referênc } \\
\text { ia }\end{array}$ & $\begin{array}{l}\text { Nome do } \\
\text { Município }\end{array}$ & $\begin{array}{l}\text { Valor } \\
\text { Adicionado } \\
\text { Bruto, a } \\
\text { preços } \\
\text { correntes, da } \\
\text { Agropecuária } \\
(\mathbf{R} \$ 1.000)\end{array}$ & $\begin{array}{l}\text { Valor } \\
\text { Adicionado } \\
\text { Bruto, a } \\
\text { preços } \\
\text { correntes, da } \\
\text { Indústria } \\
\text { (R\$ 1.000 ) }\end{array}$ & $\begin{array}{l}\text { Valor } \\
\text { adicionado } \\
\text { bruto, a preços } \\
\text { correntes, dos } \\
\text { Serviços, } \\
\text { inclusive } \\
\text { administração, } \\
\text { saúde e } \\
\text { educação } \\
\text { públicas e } \\
\text { seguridade } \\
\text { social } \\
\text { (R\$ 1.000 ) }\end{array}$ & $\begin{array}{l}\text { Valor } \\
\text { Adicionado } \\
\text { Bruto, a preços } \\
\text { correntes, da } \\
\text { Administração, } \\
\text { saúde e } \\
\text { educação } \\
\text { públicas e } \\
\text { seguridade } \\
\text { social } \\
(R \$ 1.000)\end{array}$ & $\begin{array}{l}\text { Impostos, } \\
\text { líquidos de } \\
\text { subsídios, } \\
\text { sobre produtos, } \\
\text { a preços } \\
\text { correntes } \\
(\mathbf{R} \$ 1.000)\end{array}$ & $\begin{array}{l}\text { Produto } \\
\text { Interno Bruto } \\
\text { a preços } \\
\text { correntes } \\
(\mathbf{R} \$ 1.000)\end{array}$ & $\begin{array}{l}\text { População } \\
\text { Dado disponível } \\
\text { somente para o } \\
\text { último ano da } \\
\text { série. } \\
\left(\mathrm{N}^{\circ} \text { de }\right. \\
\text { habitantes ) }\end{array}$ & $\begin{array}{l}\text { Produto } \\
\text { Interno } \\
\text { Bruto per } \\
\text { capita } \\
\text { Dado } \\
\text { disponível } \\
\text { somente para } \\
\text { o último ano } \\
\text { da série. } \\
\text { (R\$ 1,00 ) }\end{array}$ \\
\hline 1999 & Confins & 395 & 2.180 & 47.895 & 3.425 & 2.859 & 53.329 & & \\
\hline 1999 & Lagoa Santa & 4.423 & 32.011 & 95.215 & 20.918 & 22.519 & 154.168 & & \\
\hline 2000 & Confins & 925 & 2.616 & 46.213 & 4.074 & 2.645 & 52.398 & & \\
\hline 2000 & Lagoa Santa & 2.918 & 45.458 & 113.146 & 23.209 & 30.951 & 192.473 & & \\
\hline 2001 & Confins & 926 & 2.228 & 53.103 & 4.733 & 3.678 & 59.935 & & \\
\hline 2001 & Lagoa Santa & 3.107 & 49.257 & 147.429 & 28.686 & 41.603 & 241.397 & & \\
\hline 2002 & Confins & 1.030 & 3.972 & 39.398 & 5.388 & 3.768 & 48.168 & & \\
\hline 2002 & Lagoa Santa & 3.477 & 57.122 & 160.478 & 35.872 & 41.467 & 262.544 & & \\
\hline 2003 & Confins & 1.338 & 4.959 & 38.871 & 5.849 & 3.994 & 49.162 & & \\
\hline 2003 & Lagoa Santa & 6.869 & 71.237 & 171.749 & 39.240 & 44.510 & 294.365 & & \\
\hline 2004 & Confins & 1.040 & 6.070 & 46.392 & 6.403 & 5.218 & 58.721 & & \\
\hline
\end{tabular}

Revista Cerrados, Montes Claros/MG, v.16, n. 1, p. 282-308, jan./jun.-2018 
COUTINHO, R. A. F.; CARDOSO, A. D.; LESSA, S. N.

(Trans)formação do município de confins e seu planejamento territorial

\begin{tabular}{|c|c|c|c|c|c|c|c|c|c|}
\hline 2004 & Lagoa Santa & 6.599 & 102.480 & 195.270 & 45.372 & 50.121 & 354.469 & & \\
\hline 2005 & Confins & 919 & 6.258 & 219.144 & 7.933 & 162.204 & 388.524 & & \\
\hline 2005 & Lagoa Santa & 4.234 & 102.782 & 239.384 & 54.862 & 60.666 & 407.065 & & \\
\hline 2006 & Confins & 601 & 5.474 & 190.337 & 8.916 & 450.534 & 646.946 & & \\
\hline 2006 & Lagoa Santa & 3.607 & 129.599 & 286.176 & 63.041 & 69.796 & 489.180 & & \\
\hline 2007 & Confins & 477 & 8.907 & 164.355 & 9.653 & 734.754 & 908.494 & & \\
\hline 2007 & Lagoa Santa & 2.435 & 147.925 & 325.730 & 70.578 & 76.248 & 552.337 & & \\
\hline 2008 & Confins & 695 & 11.908 & 206.175 & 11.741 & 839.012 & 1.057 .790 & & \\
\hline 2008 & Lagoa Santa & 3.308 & 165.501 & 367.001 & 85.961 & 90.559 & 626.369 & & \\
\hline 2009 & Confins & 647 & 10.506 & 224.095 & 12.897 & 902.580 & 1.137 .829 & & \\
\hline 2009 & Lagoa Santa & 3.051 & 182.476 & 399.663 & 94.362 & 88.789 & 673.979 & & \\
\hline 2010 & Confins & 627 & 12.008 & 363.234 & 15.104 & 1.048 .939 & 1.424 .808 & & \\
\hline 2010 & Lagoa Santa & 3.655 & 249.074 & 477.645 & 116.075 & 115.783 & 846.157 & & \\
\hline 2011 & Confins & 618 & 14.612 & 424.526 & 17.555 & 1.100 .789 & 1.540 .545 & & \\
\hline 2011 & Lagoa Santa & 3.453 & 214.803 & 597.387 & 131.982 & 142.823 & 958.466 & & \\
\hline 2012 & Confins & 710 & 15.684 & 389.966 & 19.132 & 1.237 .547 & 1.643 .907 & 6.077 & 270.513 \\
\hline 2012 & Lagoa Santa & 3.634 & 240.244 & 667.349 & 147.358 & 169.700 & 1.080 .927 & 54.732 & 19.749 \\
\hline
\end{tabular}

Fonte: IBGE - Base de dados PIB dos municípios brasileiros 1999-2012. Base de dados IBGE. 
No tocante a economia rural de Confins, apesar de pequena em números, sua existência, com a presença de pequenos produtores e sitiantes, não justifica a extinção/supressão normativa do zoneamento rural. Conforme se verifica da tabela seguinte, e de seu respectivo gráfico, os valores advindos da agropecuária que compõem o PIB de Confins, representam quase que a metade daquela atribuída à indústria. Não há, pois, como desconsiderar e dizer inexistente a atividade agropecuária no município.

O gráfico confeccionado a partir da tabela nos dá uma leitura bem didática do que representa as riquezas geradas pela agropecuária para a economia global de Confins. Apesar de seu pico ter ocorrido em 2002, certo é que seus valores cresceram (ou praticamente dobraram) desde a primeira medição (1999, ou seja, quatro anos após a emancipação do município de Lagoa Santa), até a última medição (2012 - ou ainda, apenas três anos após a supressão da zona rural do município).

GRÁFICO 01 - Valor adicionado bruto, a preços correntes, da agropecuária (R\$1.000) em Confins/MG, 1999- 2012. Base de dados IBGE

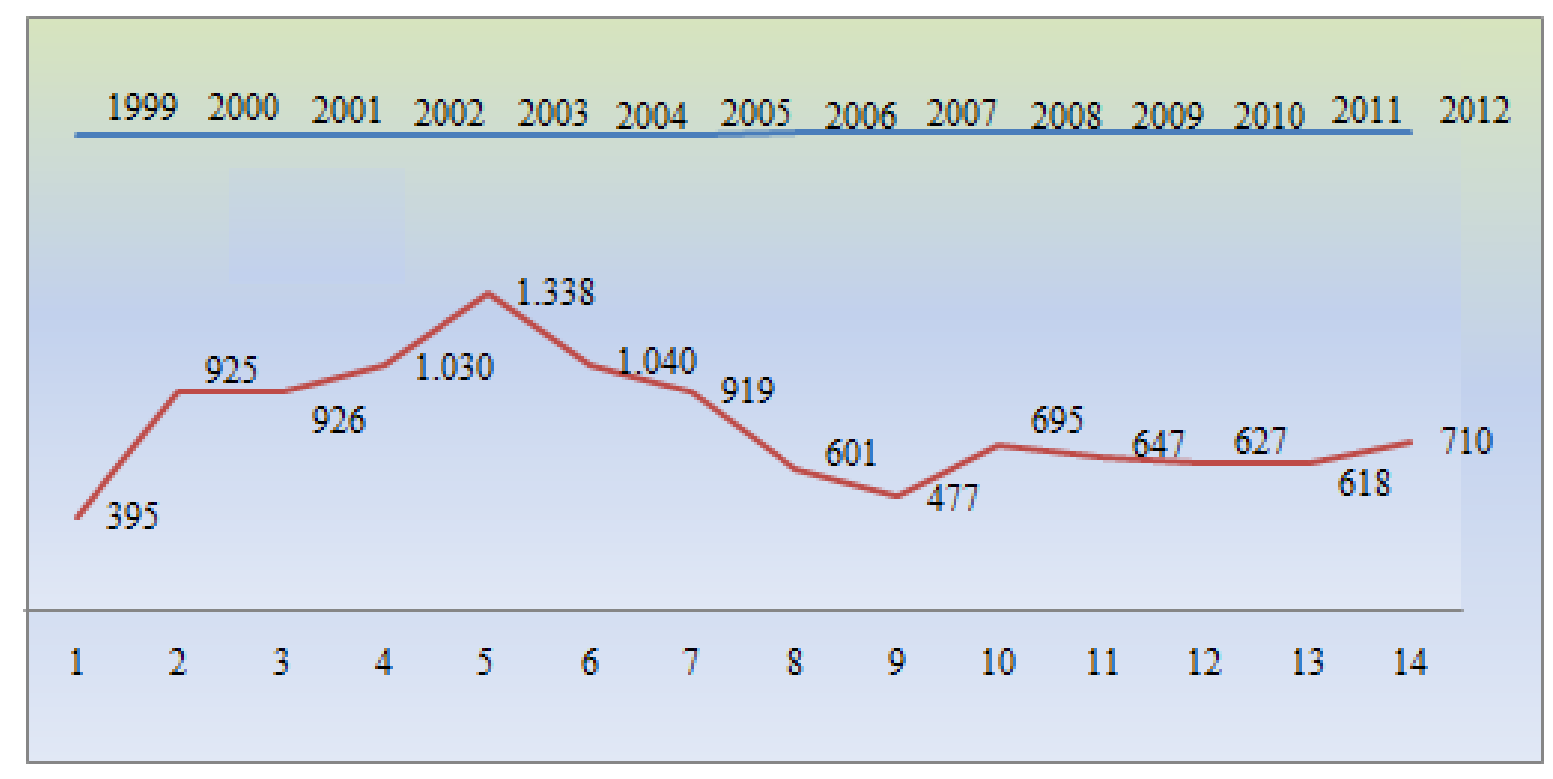

Fonte: IBGE (Elaboração dos autores).

Os dados demonstram não haver subsídios suficientes para a ação legislativa do município de Confins em suprimir do seu zoneamento as áreas rurais, sinalizando, desde já, 
que o mesmo se deu para atender ao anseio expansionista da Metropolitana, sem levar em conta, ao que tudo indica, os preceitos legitimadores do fazer ordenamento e planejamento territorial no Brasil. Pode-se dizer que o rural no município de Confins - zoneamento extirpado ante a última revisão do Plano Diretor (2009) - não só se mostra persistente, mas efetivamente existente.

É sabido que a característica principal do planejamento é equilibrar as demandas do crescimento econômico, seus resultados e as necessidades sociais. Para Lafer (1973, p. 2021):

O planejamento consiste em apontar o caminho mais racional do desenvolvimento, dadas as características da economia. O problema que se coloca é saber se o Governo dispõe de instrumentos suficientes para alocar os recursos de acordo com a orientação do plano. No sistema capitalista, a influência pode exercer-se diretamente na alocação de recursos (investimentos públicos) ou indiretamente através do sistema de preços.

Segundo Rodrigues (2009, p. 139), planejamento é:

[...] instrumento que canaliza e acelera os investimentos públicos, visando o desenvolvimento econômico para cada setor, região e conjunto da economia. Por intermédio do planejamento pode-se, teoricamente, aumentar a eficiência na utilização dos escassos recursos de que dispõem as economias e regiões subdesenvolvidas.

O planejamento urbano e territorial dos municípios tem, entre seus objetivos, o de assegurar a continuidade entre espaços naturais, rurais e urbanos. Ele pode, por um lado, exercer um papel importante de delimitação de espaços construídos de ocupação populacional densa, evitando sua dispersão excessiva no território, e, por outro lado, proteger áreas de produção agrícola e complexos ambientais culturais de interesse coletivo.

As unidades de conservação, os complexos ambientais culturais e as áreas de produção agrícola, conectados por um planejamento e ordenamento escorreitos, contribuem para reforçar a identidade cultural, local e regional, criam oportunidades de acesso público ao mundo rural e à natureza, respeitados os níveis de proteção ambiental, e oferecem um espaço de qualidade para o lazer, as atividades turísticas, a aquisição de conhecimentos e a convivência social, caracterizando, ao mesmo tempo, um instrumento de regulação e ordenamento territorial, bem como de mobilização social e de participação política. 
O que se pretende mostrar é que o controle dos espaços, através de um efetivo e correto zoneamento, pode ser garantido a partir de uma divisão do território que possa delimitar a expansão urbana e a distribuição espacial da população de forma a garantir o desenvolvimento econômico, social e o equilíbrio ambiental.

Dentro do universo do planejamento, o zoneamento é peça importante na política de desenvolvimento territorial, que nos dizeres de Mukai (2004, p. 126), consiste "na organização do espaço, levando em consideração a realidade existente e suas implicações no desenvolvimento futuro, não só do ponto de vista físico, como também social e econômico, para obter o bem-estar progressivo desta localidade."

Segundo Silva:

O zoneamento é instrumento jurídico de ordenação do uso e ocupação do solo. Em um primeiro sentido o zoneamento consiste na repartição do território municipal à vista da destinação da terra e do uso do solo, definindo, no primeiro caso, a qualificação do solo em urbano, de expansão urbana, urbanizável e rural; e no segundo dividindo o território do Município em zonas de uso. Foi sempre considerado, nesta segunda acepção, como um dos principais instrumentos do planejamento urbanístico municipal, configurando um Plano Urbanístico Espacial. (SILVA, 2007, p. 270).

Ainda segundo Silva (2007, p. 271), o objetivo e a natureza do zoneamento constituem-se:

[...] em qualquer de suas qualificações (Urbano, Ambiental, Industrial), um procedimento urbanístico que tem por objetivo regular o uso da propriedade do solo e dos edifícios em áreas homogêneas no interesse coletivo do bem estar da população. [...]. Não é modo de excluir uma atividade indesejável, descarregando-a nos Municípios vizinhos. Não é meio de segregação racial ou social. Não terá por objetivo satisfazer interesses particulares, nem de determinados grupos. Não será um sistema para realizar discriminação de qualquer tipo. Para ser legítimo, há de ter objetivos públicos, voltados para a realização da qualidade de vida das populações.

A visão tradicionalista de que o planejamento se ateria apenas no tocante ao solo urbano vai ficando ultrapassada, tendo em vista a conscientização, cada vez maior, dos órgãos de controle social e de formação da opinião pública. Atualmente há uma maior ênfase aos problemas socioculturais e ambientais da nossa época, e, portanto, de todos os aspectos do território global dos municípios.

Revista Cerrados, Montes Claros/MG, v.16, n. 1, p. 282-308, jan./jun.-2018. 
COUTINHO, R. A. F.; CARDOSO, A. D.; LESSA, S. N.

(Trans)formação do município de confins e seu planejamento territorial

Com base em tais concepções doutrinárias, ao que tudo indica, a revisão do Plano Diretor de Confins (LC 12/2009), que simplesmente extirpou do zoneamento municipal as áreas rurais, não só ofendeu os "preceitos legitimadores" do ordenamento e planejamento territorial, como foi de encontro a tudo o que o que está sendo preconizado pelo planejamento regional, materializado no PDDI e no MZ-RMBH.

\section{CONSIDERAÇÕES FINAIS}

O PDDI-RMBH, assim como o MZ-RMBH, traçou um diagnóstico abrangente e atualizado sobre o estado da $\mathrm{RMBH}$, assim como de suas mais recentes tendências de transformação sobre o Uso do Solo, Dinâmica Imobiliária e Escalas de Centralidades Metropolitanas (USDEC - MZ-RMBH).

As atribuições territoriais impostas a Confins desde a sua emancipação (1995), se deram, primordialmente, por diretrizes e ações governamentais de expansão da Metropolitana, que culminaram com o redesenho do espaço rural/urbano de Confins. Foram estimuladas e impostas atividades outras, que não aquelas de aptidão natural. Num primeiro momento, mais precisamente na década de 1980, para viabilizar o crescimento urbano da metrópole e também a vetorização norte da Metropolitana, instalou-se o AITN em Confins.

Num segundo momento, quando o AITN passou a operar os principais voos transferidos do Aeroporto da Pampulha (2005), e, consequentemente, com a implementação do Vetor Norte (construção da Linha Verde/2007, via de trânsito rápido na Av. Cristiano Machado e outras vias de acesso entre Belo Horizonte e Confins; construção da Cidade Administrativa no limite norte de Belo Horizonte/2010), mais uma vez a ação governamental se constituiu como mola propulsora para se dar novo dinamismo à região, implicando em importantes desdobramentos sobre a política territorial dos municípios que fazem parte do Vetor Norte, em especial Confins, trazendo em seu rastro alterações substanciais sobre o modo de vida dos moradores do município.

Com isso Confins passou, assim como vem passando, por um intenso e frenético processo de "urbanização", que não necessariamente traduziu na transformação do município 
COUTINHO, R. A. F.; CARDOSO, A. D.; LESSA, S. N.

(Trans)formação do município de confins e seu planejamento territorial

numa "nova centralidade", fato que ora se tenta transmudar com as ações planificadas no PDDI e no MZ-RMBH.

O município de Confins, remontando-se os processos históricos de territorialização, foi visto e tratado tão somente como área/território para atender ao expansionismo da Metropolitana, priorizando, assim, apenas a uma perspectiva e demanda econômica, deixando de lado seus registros históricos de atividades socioeconômicas e as demandas socioculturais.

Atestou-se a hipótese, ou mesmo a premissa, de que a supressão da zona rural do município de Confins através da mera revisão de seu Plano Diretor (LC 12/2009), teve como fundamento atender aos anseios do capital e da especulação imobiliária; a mais-valia fundiária. Pode-se confirmar que o município de Confins não aceitou passivamente às investidas e intervenções do Estado (requalificação do AITN, Cidade Administrativa, Linha Verde - Vetor Norte). Percebeu-se também que, num segundo movimento, as relações socioespaciais foram drasticamente alteradas, interferindo no assentamento da população do município de Confins, de forma mais abrangente que no primeiro momento, pois não afetou apenas a população da área do empreendimento diretamente envolvida (AITN), mas de toda a população das áreas/zonas rurais suprimidas.

\section{AGRADECIMENTOS}

À Coordenação de Aperfeiçoamento de Pessoal de Nível Superior (CAPES) pela concessão de bolsas de estudos.

\section{REFERÊNCIAS}

BRASIL. Constituição da República Federativa do Brasil. Brasília, DF, 1988.

Lei $\mathbf{n}^{0}$ 13.089, de 12 de janeiro de 2015. Institui o Estatuto da Metrópole e dá outras providências. Brasília, DF, 2015.

. Lei Complementar $n^{\circ}$ 14, de 8 de junho de 1973. Estabelece as regiões

metropolitanas de São Paulo, Belo Horizonte, Porto Alegre, Recife, Salvador, Curitiba, Belém e Fortaleza. Brasília, DF, 1973. 
COUTINHO, R. A. F.; CARDOSO, A. D.; LESSA, S. N.

(Trans)formação do município de confins e seu planejamento territorial

Presidência da República. Lei no 10.257, de 10 de julho de 2011. Dispõe sobre o Estatuto da Cidade e dá outras providências. Brasília, DF, 2001.

Cedeplar/UFMG. Macrozoneamento da Região Metropolitana de Belo Horizonte Marco Teórico-Metodológico e Definição das Áreas Temáticas Afetas ao interesse Metropolitano - MZ. Secretaria de Estado de Desenvolvimento Regional e Política Urbana. Minas Gerais, Belo Horizonte, fevereiro de 2014.

. Macrozoneamento da Região Metropolitana de Belo Horizonte - Produto

Final. Secretaria de Estado de Desenvolvimento Regional e Política Urbana. Minas Gerais, Belo Horizonte, abril de 2016.

Plano Diretor de Desenvolvimento Integrado da Região Metropolitana de Belo Horizonte - PDDI-RMBH - Produto VI - Relatório Final - Definição das Propostas de Políticas Setoriais, Projetos e Investimentos Prioritários. Secretaria de Estado de Desenvolvimento Regional e Política Urbana. Minas Gerais, Belo Horizonte, maio de 2011.

Proposta de estudos referenciais e elaboração de estratégias de ação para o planejamento do desenvolvimento integradoda região metropolitana de belo horizonte: Marco Teórico-Metodológico e Síntese dos Estudos Setoriais. (Relatório Parcial). Minas Gerais, Belo Horizonte, julho 2010.

Confins. Lei Complementar $n^{\circ}$ 002, 1999, de 30 de dezembro de 1999. Institui o Plano Diretor do Município de Confins e dá outras providências. Minas Gerais, Confins, 30 de dezembro de 1999.

Lei Complementar $\mathbf{n}^{\circ} 012$, de 25 de maio de 2009. Dispõe sobre a revisão da Lei Complementar $n^{\circ}$ 002/99, que institui o Plano Diretor de Confins. Minas Gerais, Confins, de 25 de maio de 2009.

CORRÊA, Roberto Lobato. O espaço urbano. 2. ed. São Paulo: Editora Ática, 1989, p. 96.

COSTA, Heloísa S. de M. Mercado imobiliário, estado e natureza na produção do espaço metropolitano. In: Heloisa Soares de Moura Costa; Geraldo Magela Costa; Jupira Gomes de Mendonça; Roberto Luís de Melo Monte-Mór. (Org.). Novas Periferias Metropolitanas. Belo Horizonte: Editora C/Arte, 2006, v. 1, p. 101-124.

COUTINHO, Rogério Augusto Figueiredo Coutinho. A Metropolização de Confins: a intervenção do Estado e sua transformação socioespacial. 2017. 98f. Dissertação (Mestrado em Desenvolvimento Social) - Programa de Pós-graduação em Desenvolvimento Social da Universidade Estadual de Montes Claros - UNIMONTES, Minas Gerais, Montes Claros, 2017.

INSTITUTO BRASILERO DE GEOGRAFIA E ESTATÍSTICA - IBGE (2015). "Área Territorial Oficial". Rio de Janeiro: IBGE, 2015.

Revista Cerrados, Montes Claros/MG, v.16, n. 1, p. 282-308, jan./jun.-2018. 
COUTINHO, R. A. F.; CARDOSO, A. D.; LESSA, S. N.

(Trans)formação do município de confins e seu planejamento territorial

. Base de dados PIB dos municípios brasileiros 1999-2012. Base de dados IBGE.

Rio de Janeiro: IBGE, 2012.

. Censo Demográfico. Rio de Janeiro: IBGE, 1991.

. Censo Demográfico. Rio de Janeiro: IBGE, 2000.

. Censo Agropecuário de 2006. Rio de Janeiro: IBGE, 2006.

. Censo Demográfico. Rio de Janeiro: IBGE, 2010.

. Estimativas populacionais para os municípios brasileiros em 01.07.2015. Rio de Janeiro IBGE, 2015.

Manual Técnico de Uso da Terra, 2. Ed. Rio de Janeiro: IBGE, 2006.

Produto Interno Bruto (PIB) Per Capita, 2010. Rio de Janeiro: IBGE, 2010.

. Produto Interno Bruto dos Municípios 2013. Instituto Brasileiro de Geografia e

Estatística (IBGE). Rio de Janeiro: IBGE, 2015.

INSTITUTO HORIZONTES. Programa de Desenvolvimento e Gestão da Região

Metropolitana de Belo Horizonte. Vetor Norte da RMBH. Programa De Ações

Imediatas.”, Instituto Horizontes, 2004.

INSTITUTO DE PESQUISA ECONÔMICA APLICADA - IPEA (2015). Governança Metropolitana no Brasil. Relatório de Pesquisa Caracterização e Quadros de Análise Comparativa da Governança Metropolitana no Brasil: arranjos institucionais de gestão metropolitana (Componente 1). Região Metropolitana de Belo Horizonte. Rio de Janeiro, 2015, p. 7.

LAFER, B. M. Planejamento no Brasil. São Paulo: Perspectiva, 1973.

LEFEBVRE, Henri. A vida cotidiana no mundo moderno. São Paulo: Ática, 1991.

A revolução urbana. Tradução de Sérgio Martins. Belo Horizonte: Ed. UFMG, 1999. Título original: La révolution urbaine.

. A revolução urbana. Belo Horizonte: ed. UFMG, 2004.

. O direito à cidade. São Paulo: Centauro Editora, 2001.

. O direito à cidade. São Paulo: Centauro Editora, 2008. 
COUTINHO, R. A. F.; CARDOSO, A. D.; LESSA, S. N.

(Trans)formação do município de confins e seu planejamento territorial

MINAS GERAIS. Lei no 1.039 , de 12 de dezembro de 1953. ESTABELECE A DIVISÃO ADMINISTRATIVA E JUDICIÁRIA DO ESTADO, A VIGORAR DE $1^{\circ}$ DE JANEIRO DE 1954 A 31 DE DEZEMBRO DE 1958 E DÁ OUTRAS

PROVIDÊNCIAS. Minas Gerais, Belo Horizonte, 12 de dezembro de 1953.

Lei $n^{\circ}$ 6.303, de 30 de abril de 1974. Dispõe sobre a Região Metropolitana de

Belo Horizonte e dá outras providências. Minas Gerais, Belo Horizonte, p. 7, 1 de maio de 1974.

Lei n ${ }^{\circ} 12.030$, de 21 de dezembro de 1995. Cria Municípios e dá outras providências. Minas Gerais, Belo Horizonte, 21 de dezembro de 1995.

Lei Complementar $n^{\circ}$ 88, de 12 de janeiro de 2006. Dispõe sobre a instituição e a gestão de região metropolitana e sobre o Fundo de Desenvolvimento Metropolitano. Minas Gerais, Belo Horizonte, 12 de janeiro de 2006.

Lei Complementar $n^{\circ}$ 89, de 12 de janeiro de 2006. Dispõe sobre a Região

Metropolitana de Belo Horizonte. Minas Gerais, Belo Horizonte, 12 de janeiro de 2006.

RIBEIRO, Luiz César de Queiroz; AZEVEDO, Sergio de. (Org.). A crise da moradia nas grandes cidades: da questão da habitação à reforma urbana. Rio de Janeiro: Editora UFRJ, 1996.

RIBEIRO, Luis César de Queiroz. Dos cortiços aos condomínios fechados: as formas de produção da moradia na cidade do Rio de Janeiro. Rio de Janeiro: Civilização Brasileira, 1997.

RODRIGUES, L. Itinerário da construção das abordagens de desenvolvimento. In:

Argumentos: Dossiê Desenvolvimento Social. Montes Claros, MG: Editora Unimontes, 2009. V.3, n.1, dez de 2009. p. 139.

SALGADO, Silvia Regina da Costa. Experiências Municipais e Desenvolvimento Local. São Paulo em Perspectiva-Revista da Fundação Seade. São Paulo. v.10, n.3, jul.set/1996. 48$52 \mathrm{p}$.

SANTOS, Milton. A natureza do espaço: técnica e tempo, razão e emoção. São Paulo: Editora da Universidade de São Paulo, 2002.

Técnica, espaço, tempo: globalização e meio técnico-científico-informacional. São Paulo: Hucitec, 1998.

A urbanização brasileira. São Paulo: Edusp, 2008.

SILVA, José Afonso da. Direito Ambiental Constitucional. 6. ed. São Paulo: Malheiros, 2007, p. 270. 
COUTINHO, R. A. F.; CARDOSO, A. D.; LESSA, S. N.

(Trans)formação do município de confins e seu planejamento territorial

SILVA, J. M. Cultura e Territorialidades Urbanas, uma abordagem da pequena cidade.

Revista de História Regional, v.5, n.2, ano 2000.

\section{Autores}

Rogério Augusto Figueiredo Coutinho - Possui Graduação em Direito pela Universidade de Uberaba (UNIUBE) e Mestrado em Desenvolvimento pela Universidade Estadual de Montes Claros (UNIMONTES). Atualmente trabalha no Instituto Brasileiro de Geografia e Estatística (IBGE).

Antônio Dimas Cardoso - Possui Graduação em Ciências Sociais pela Universidade Estadual de Montes Claros (UNIMONTES), Mestrado e Doutorado em Sociologia, ambos cursados pela Universidade de Brasília (UnB). Atualmente é Professor do Departamento de Política e Ciências Sociais e do Programa de Pós-Graduação em Desenvolvimento Social da Universidade Estadual de Montes Claros (UNIMONTES).

Simone Narciso Lessa - Possui Graduação em História pela Universidade Federal de Minas Gerais (UFMG), Mestrado e Doutorado em História pela Universidade Estadual de Campinas (UNICAMP). Atualmente é Professora do Programa de Pós-Graduação em Desenvolvimento Social da Universidade Estadual de Montes Claros (UNIMONTES).

Artigo recebido em: 12 de maio de 2018.

Artigo aceito em: 28 de junho de 2018.

Artigo publicado em: 30 de junho de 2018. 